\title{
Effect of Glass Powder on Concrete Sustainability
}

\author{
Ablam Zidol', Monique Tohoue Tognonvi' ${ }^{2}$, Arezki Tagnit-Hamou1 \\ ${ }^{1}$ Department of Civil Engineering, University of Sherbrooke, Quebec, Canada \\ ${ }^{2}$ Department of Biological Sciences, University of Peleforo-Gbon-Coulibaly, Korhogo, Côte d'Ivoire \\ Email: Monique.tognonvi@gmail.com
}

How to cite this paper: Zidol, A., Tognonvi, M.T. and Tagnit-Hamou, A. (2017) Effect of Glass Powder on Concrete Sustainability. New Journal of Glass and Ceramics, 7, 34-47.

https://doi.org/10.4236/njgc.2017.72004

Received: February 15, 2017

Accepted: April 27, 2017

Published: April 30, 2017

Copyright $\odot 2017$ by authors and Scientific Research Publishing Inc. This work is licensed under the Creative Commons Attribution International License (CC BY 4.0).

http://creativecommons.org/licenses/by/4.0/

\begin{abstract}
As defined by the American Concrete Institute (ACI), alternative supplementary cementitious materials (ASCMs) and local materials are very important in concrete sustainability. As an ASCM, glass powder (GP) shows excellent pozzolanic properties. This paper focuses on characterization and the effect of GP on concrete properties compared to those of Class F fly ash (FFA) and ground granulated blast furnace slag (GGBS). Concrete incorporating 0, 20 and $30 \%$ of GP and other concrete mixes containing $30 \%$ of FFA or GGBS were cast. The concrete mixes considered in this study have water to binder (w/b) mass ratio ranging from 0.35 to 0.65 . The mechanical properties such as compressive strength and durability including chloride ions permeability and chloride ions diffusion are evaluated. The results show that GP develops effects on mechanical properties similar to those of FFA and performs better than GGBS and FFA in terms of permeability reduction. GP reduces dramatically chloride permeability of concrete regardless w/b ratio, favoring an improvement of the concrete durability. Because of the interesting permeability developed by concretes incorporating GP, its use as an ASCM is promising.
\end{abstract}

\section{Keywords}

Glass Powder, Concrete, Sustainability, Alternative Supplementary Cementitious Materials, Permeability

\section{Introduction}

Mineral additions are commonly used in concrete as useful components. The decrease of the permeability of concrete containing mineral additives is considered as an important aspect of their beneficial effects. Several studies [1] [2] [3] showed that the cement pastes containing mineral additives including FFA, silica 
fume and rice husk ash reduce significantly the total porosity with more disconnected capillary network compared to that of ordinary Portland cement (OPC) pastes. These changes are qualitatively correlated with the reduction in permeability. The pozzolanic reaction seems able to develop easily discontinuous pores [4]. The incorporation of FFA in concrete can reduce the water need of about 5 to $15 \%$ compared to OPC [5]. This reduction in water is often attributed to the spherical shape of FFA particles. Fly ash and slag significantly reduce the alkali aggregate reaction. The use of $40 \%$ ground granulated slag in concrete is very effective in reducing the in situ sorptivity of concrete [6].

In addition to these conventional mineral admixtures, other materials such as glass powder could be used as an alternative cementitious material. The effects of GP are quite similar to those of conventional supplementary cementitious materials (SCMs) on the main properties of concrete. The use of crushed glass as GP in concrete is relatively recent. The high alkali content of the glass makes easier the development of alkali-silica reaction that can generate damaging stresses and cracking in concrete, when glass is used as aggregate. Yet when it is ground into fine powder and used as partial replacement of cement, it develops a pozzolanic reaction which has a positive effect on the main properties of concrete and also helps to reduce the expansion of concrete due to alkali-silica reaction (ASR). Several studies have reported the reduction of expansion due to ASR in the presence of GP [7] [8] [9]. Samtur [10] achieved the same conclusion which provides that GP with particle size $<75$ microns could act as a pozzolanic material and reduce the expansion due to ASR. The issue of GP particles size which can develop a pozzolanic activity with positive effect despite the ASR which has a negative effect, has been addressed by several other authors [11]-[16]. They reported that more glass powder particles are finer, more the expansion is reduced.

Recent research has shown that glass powder, obtained from grinding bottles soda-lime glass, develops pozzolanic properties and can be used as SCM [15] [16] [17] [18] [19]. The pozzolanic activity increases with the fineness of GP [15] [16] [20] [21]. When used as a partial replacement of OPC in concrete, glass powder develops performance relatively closed to the one of fly ash. GP significantly reduces the chloride ions permeability in concrete. It is more efficient in concrete with high w/b mass ratio than low w/b. After 56 days of curing, the control concrete having a low w/b of 0.35 has a chloride permeability greater than that of concrete with high w/b of 0.65 and containing glass powder [22]. Shayan et al. have shown that at constant water to binder mass ratio, the addition of $20 \%$ of GP (particle size $<10$ microns) significantly reduces the chloride ion permeability of concrete [7]. This result was confirmed by Schawrz et al. [23]. This paper focuses primarily on the effects of glass powder on the main transport properties of concrete which are responsible for the resistance against the penetration of external agents potentially aggressive. The effects of glass powder on the concrete properties are compared to those of other mineral admixtures such as class FFA and ground granulated blast furnace slag (GGBS). 


\section{Materials and Methods}

\subsection{Materials}

Coarse aggregates from crushed limestone, and an alluvial sand provided by a local company DJL are used for concrete production.

Cementitious materials used in this study, are (general use) Portland cement (GU), GP, class FFA and GGBS. The glass powder is a by-product obtained by grinding mixed soda-lime glass (scrap glass of different colors). FFA is an ASTM (American Society for Testing and Materials) class FFA [ASTM C618]. GGBS is a slag according to ASTM C989.

Physical and chemical characteristics of these materials are presented in Table 1 and Table 2. The average diameter of cement particles is around $14.9 \mu \mathrm{m}$ while that of GP, FFA and GGBS particles are respectively 10.9, 9.2 and $8.4 \mu \mathrm{m}$.

\subsection{Tests}

1) Compressive strength

Compressive strength tests are conducted on the $100 \times 200 \mathrm{~mm}$ cylinders in accordance with ASTM C39.

2) Chloride ions permeability

Permeability tests are performed on disks of $95 \mathrm{~mm}$ in diameter and $50 \mathrm{~mm}$ thick from cylinders of $100 \times 200 \mathrm{~mm}$ in size. These tests are performed according to ASTM C1202.

3) Chloride diffusion

This test is performed on disks of $95 \mathrm{~mm}$ in diameter and $50 \mathrm{~mm}$ thick from the $100 \times 200 \mathrm{~mm}$ cylinders in accordance with AFPC-AFREM (AFPC: Association française pour la construction-AFREM: Association française pour la recherche et les essais sur les matériaux et les constructions). The test consists in applying a potential difference (ddp) of $30 \mathrm{~V}$ across a disk, with one end immersed in a solution of $0.1 \mathrm{M} \mathrm{NaOH}$ and $0.5 \mathrm{M} \mathrm{NaCl}$ and the other end in $0.1 \mathrm{M}$ $\mathrm{NaOH}$, to accelerate the penetration of chlorides. The terminal containing $\mathrm{NaCl}$

Table 1. Physical characteristics.

\begin{tabular}{ccccc}
\hline \multirow{2}{*}{ Characteristics } & \multicolumn{3}{c}{ Materials } \\
\cline { 2 - 4 } & OPC & GP & FFA & GGBS \\
Density & 3.15 & 2.54 & 2.67 & 2.93 \\
Blaine Fineness $\left(\mathrm{m}^{2} / \mathrm{kg}\right)$ & 382 & 440 & 350 & 526 \\
\hline
\end{tabular}

Table 2. Chemical analysis.

\begin{tabular}{ccccccccccc}
\hline \multirow{2}{*}{ Materials } & \multicolumn{10}{c}{ Chemical composition } \\
\cline { 2 - 10 } & $\mathrm{SiO}_{2}$ & $\mathrm{Al}_{2} \mathrm{O}_{3}$ & $\mathrm{Fe}_{2} \mathrm{O}_{3}$ & $\mathrm{CaO}$ & $\mathrm{MgO}$ & $\mathrm{SO}_{3}$ & $\mathrm{~K}_{2} \mathrm{O}$ & $\mathrm{Na}_{2} \mathrm{O}$ & LOI & $\mathrm{Na}_{2} \mathrm{O}_{\text {eq }}$ \\
\hline Cement (GU) & 20.43 & 4.70 & 2.92 & 62.39 & 1.81 & 3.53 & 0.95 & 0.18 & 2.51 & 0.80 \\
Glass Powder & 72.66 & 1.57 & 0.39 & 11.41 & 1.24 & 0.07 & 0.54 & 12.89 & 0.38 & 13.24 \\
Fly ash F & 49.92 & 27.61 & 12.28 & 3.71 & 0.93 & 0.30 & 1.82 & 0.35 & 1.90 & 1.54 \\
GGBS & 37.79 & 7.83 & 0.66 & 40.33 & 10.32 & 0.65 & 0.44 & 0.19 & 0.81 & 0.48 \\
\hline
\end{tabular}


and $\mathrm{NaOH}$ is the negative terminal and the other one which only contains the $\mathrm{NaOH}$ solution is the positive terminal of the circuit arrangement for the test. The experimental device to apply this voltage on the sample is turned off after a time of about 72 hours. The sample to test is recovered and then cracked in half and sprayed with a solution of silver nitrate. Chloride containing parts keep the color of concrete and healthy parts are rust colored. From this observed coloration, the depth of chlorides penetration was measured using a ruler. This measured depth allows to calculate with the standard formulas, the apparent diffusion coefficient of chloride ions.

\subsection{Mix Design}

Concrete mixes of this study have w/b mass ratio ranging from 0.65 to 0.35 . The main $\mathrm{w} / \mathrm{b}$ ratios considered are $0.65,0.55,0.40$ and 0.35 with respective binder dosages of $300 ; 350 ; 400$ and $430 \mathrm{~kg} / \mathrm{m}^{3}$. For each w/b ratio, 5 concrete mixes depending on the type of SCMs and their incorporation rate are produced. For each w/b ratio, there are: concrete containing only "GU" Portland cement (referenced as control); concrete containing $20 \%$ or $30 \%$ of glass powder as a partial replacement of cement by mass identified respectively by (20GP) and (30GP), concrete containing $30 \%$ of fly ash F (30FAF) or ground granulated blast furnace slag (30GGBS). An air entraining agent was systematically incorporated into all concrete mixes to obtain the required air content. No chemical admixture is used to adjust the slump of concrete with w/b $=0.55$ or 0.65 (Table $3 \&$ Table 4). However, a superplasticizer is used in concrete mixes with $\mathrm{w} / \mathrm{b}=0.35$ and 0.40 (Table 5 \& Table 6) to adjust the slump in the same order of magnitude for concrete mixes with same $\mathrm{w} / \mathrm{b}$ ratio.

\section{Results}

\subsection{Fresh Concrete Properties}

Fresh concrete properties like initial slump and air content are shown in Table

7. Concretes with a relatively high $\mathrm{w} / \mathrm{b}$ corresponding to 0.65 or 0.55 provided

Table 3. Concretes mixes with $w / b=0.65$.

\begin{tabular}{|c|c|c|c|c|c|}
\hline Mixes & Control & 20GP & $30 \mathrm{GP}$ & $30 \mathrm{FFA}$ & 30GGBS \\
\hline GU Cement (kg) & 300 & 240 & 210 & 210 & 210 \\
\hline Glass Powder (kg) & 0 & 60 & 90 & 0 & 0 \\
\hline Fly Ash (kg) & 0 & 0 & 0 & 90 & 0 \\
\hline Slag (kg) & 0 & 0 & 0 & 0 & 90 \\
\hline Water (kg) & 195 & 195 & 195 & 195 & 195 \\
\hline Water/cement ratio & 0.65 & 0.81 & 0.93 & 0.93 & 0.93 \\
\hline Sand $0-5 \mathrm{~mm}$ abs $1.16(\mathrm{~kg})$ & 674 & 662 & 656 & 649 & 668 \\
\hline Aggregates 5 - $14 \mathrm{~mm}$ abs $0.47(\mathrm{~kg})$ & 856 & 856 & 856 & 856 & 856 \\
\hline Aggregates 10 - $20 \mathrm{~mm}$ abs $0.34(\mathrm{~kg})$ & 214 & 214 & 214 & 214 & 214 \\
\hline AEA (Airex-L) (ml/100kg) & 38 & 37 & 19 & 96 & 52 \\
\hline
\end{tabular}


Table 4. Concretes mixes with $\mathrm{w} / \mathrm{b}=0.55$.

\begin{tabular}{cccccc}
\hline Mixes & Control & 20GP & 30GP & 30FFA & 30GGBS \\
\hline GU Cement (kg) & 350 & 280 & 245 & 245 & 245 \\
Glass Powder (kg) & 0 & 70 & 105 & 0 & 0 \\
Fly Ash (kg) & 0 & 0 & 0 & 105 & 0 \\
Slag (kg) & 0 & 0 & 0 & 0 & 105 \\
Water (kg) & 192.5 & 192.5 & 192.5 & 192.5 & 192.5 \\
Water/cement ratio & 0.55 & 0.69 & 0.79 & 0.79 & 0.79 \\
Sand 0 - 5 mm abs 1.16 (kg) & 639 & 625 & 618 & 619 & 631 \\
Aggregates 5 - 14 mm abs 0.47 (kg) & 856 & 856 & 856 & 856 & 856 \\
Aggregates 10 - 20 mm abs 0.34 (kg) & 214 & 214 & 214 & 214 & 214 \\
AEA (Airex-L) (ml/100kg) & 57 & 50 & 29 & 114 & 60 \\
\hline
\end{tabular}

Table 5. Concretes mixes with $\mathrm{w} / \mathrm{b}=0.40$.

\begin{tabular}{cccccc}
\hline Mixes & Control & 20GP & 30GP & 30FFA & 30GGBS \\
\hline Cement GU (kg) & 400 & 320 & 280 & 280 & 280 \\
Glass Powder (kg) & 0 & 80 & 120 & 0 & 0 \\
Fly Ash (kg) & 0 & 0 & 0 & 120 & 0 \\
Slag (kg) & 0 & 0 & 0 & 0 & 120 \\
Water (kg) & 160 & 160 & 160 & 160 & 160 \\
Water/cement ratio & 0.40 & 0.50 & 0.57 & 0.57 & 0.57 \\
Sand 0 - 5 mm abs 1.16 (kg) & 690 & 673 & 664 & 654 & 679 \\
Aggregates 5 - 14 mm abs 0.47 (kg) & 856 & 856 & 856 & 856 & 856 \\
Aggregates 10 - 20 mm abs 0.34 (kg) & 214 & 214 & 214 & 214 & 214 \\
AEA (Airex-L) (ml/100kg) & 0 & 0 & 0 & 0 & 0 \\
AEA (Airextra) (ml/100kg) & 89 & 94 & 111 & 178 & 144 \\
Superplasticizer (Plastol 5000) $\left(\mathrm{l} / \mathrm{m}^{3}\right)$ & 2.33 & 2.18 & 2.00 & 2.22 & 2.22 \\
\hline
\end{tabular}

Table 6. Concretes mixes with $\mathrm{w} / \mathrm{b}=0.35$.

\begin{tabular}{cccccc}
\hline Mixes & Control & 20GP & 30GP & 30FFA & 30GGBS \\
\hline Cement GU (kg) & 430 & 344 & 301 & 301 & 301 \\
Glass Powder (kg) & 0 & 86 & 129 & 0 & 0 \\
Fly Ash (kg) & 0 & 0 & 0 & 129 & 0 \\
Slag (kg) & 0 & 0 & 0 & 0 & 129 \\
Water (kg) & 150.5 & 150.5 & 150.5 & 150.5 & 150.5 \\
Water/cement ratio & 0.35 & 0.44 & 0.50 & 0.50 & 0.50 \\
Sand 0 - 5 mm abs 1.16 (kg) & 691 & 672 & 662 & 652 & 679 \\
Aggregates 5 - 14 mm abs 0.47 (kg) & 856 & 856 & 856 & 856 & 856 \\
Aggregates 10 - 20 mm abs 0.34 (kg) & 214 & 214 & 214 & 214 & 214 \\
AEA (Airex-L) (ml/100kg) & 103 & 93 & 134 & 134 & 103 \\
AEA (Airextra) (ml/100kg) & 0 & 0 & 0 & 0 & 0 \\
Superplasticizer (Plastol 5000) $\left(\mathrm{l} / \mathrm{m}^{3}\right)$ & 2.67 & 2.22 & 1.78 & 1.89 & 2.22 \\
\hline
\end{tabular}


Table 7. Fresh concrete properties.

\begin{tabular}{ccccccccccc}
\hline \multirow{3}{*}{ w/b } & \multicolumn{4}{c}{ Initial slump $(\mathrm{mm})$} & \multicolumn{5}{c}{ Entrained air content (\%) } \\
\cline { 2 - 10 } & Cont & $20 \mathrm{GP}$ & $30 \mathrm{GP}$ & 30FFA & 30GGBS & Cont & 20GP & 30GP & 30FFA & 30GGBS \\
\hline 0.65 & 170 & 195 & 190 & 190 & 195 & 5.4 & 7.0 & 6.2 & 5.5 & 7.5 \\
0.55 & 200 & 195 & 195 & 200 & 170 & 7.2 & 7.4 & 5.8 & 6.6 & 7.3 \\
0.40 & 220 & 230 & 230 & 240 & 240 & 6.8 & 5.5 & 6.6 & 7.6 & 6.9 \\
0.35 & 230 & 230 & 220 & 195 & 230 & 6.6 & 6.0 & 7.2 & 6.0 & 6.4 \\
\hline
\end{tabular}

an initial slump of $185+15 \mathrm{~mm}$. As the w/b ratio is high, initial concrete slumps are also correspondingly high although there was no use of superplasticizer or water reduction agent. High slump significantly make easier air entrainment in these concrete mixes. In concrete with relatively low w/b, i.e. 0.40 or 0.35 , initial slump is about $210+30 \mathrm{~mm}$ with superplasticizer. Whatever the w/b ratio, the entrained air content varies between $5 \%$ and $8 \%$ which is the range recommended by the Canadian CSA A23.1-04 standard for an appropriate protection of concretes against gel and possibly sulphate attacks.

\subsection{Compressive Strength}

Concrete compressive strength presented in Figure 1 shows on the one hand the strength development with age and on the other hand a comparison of this strength between various mixtures at a given age. All the mixtures incorporating cement addition show initial strength (at 1 day) less than control mixtures. This observation is due to a diluting effect which is the immediate consequence from the substitution of a more reactive powder (cement) by a less reactive one (SCM). Concrete compressive strengths with SCMs are less than the ones of control up to 56 days for concrete of 0.65 and $0.55 \mathrm{w} / \mathrm{b}$ ratio; up to 91 days for those with $0.40 \mathrm{w} / \mathrm{b}$ ratio and to 1 year for the ones with lower ratio of 0.35 . This shows that the concrete incorporating SCMs with higher w/b ratio (0.65 and $0.55)$ has developed more quickly a strength similar to the control one. It means that concretes incorporating SCMs made with high w/b ratio provide a strength development rate higher than those incorporating the same mineral additions but made with a lower w/b ratio. These observations indicate an increase in the strength development rate with an increase in $\mathrm{w} / \mathrm{b}$ ratio of concretes incorporating mineral additives. This result is in accordance with previous studies reporting that concrete with SCMs seem to perform better with high w/b than low one [22] [24]. As these additions develop after the cement hydration a more or less pozzolanic reaction according to their reactivity, they need a quantity of free water available to keep on in an optimal way this reaction. With high w/b ratio, there is enough free water available to further continuation of the optimal reaction of these additions. This explains the trend observed in the strength development in the long term of concretes of different $w / b$ ratio. Indeed, concrete containing mineral additives made with high w/b developed strength higher than those of control concretes before one year while those with lower ratio of 


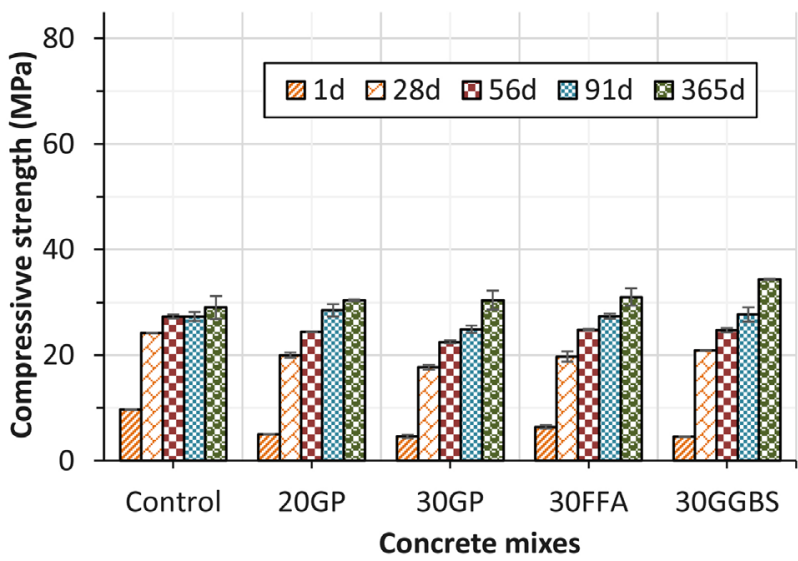

(a)

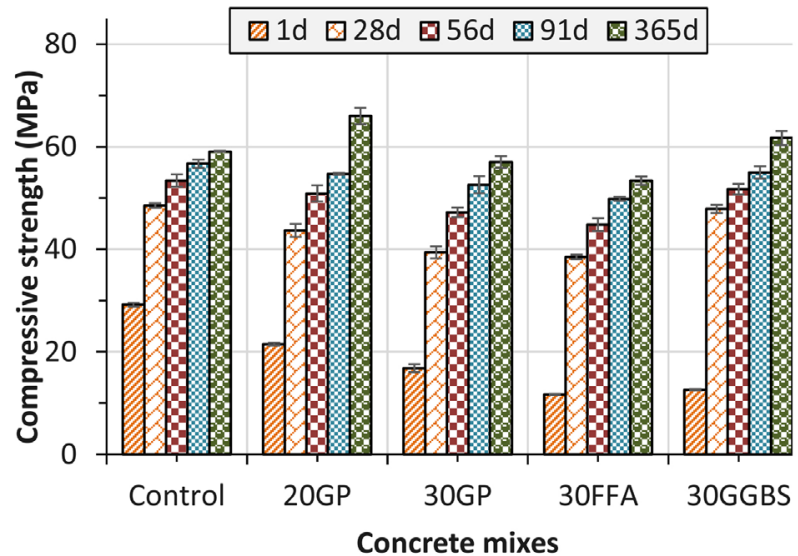

(c)

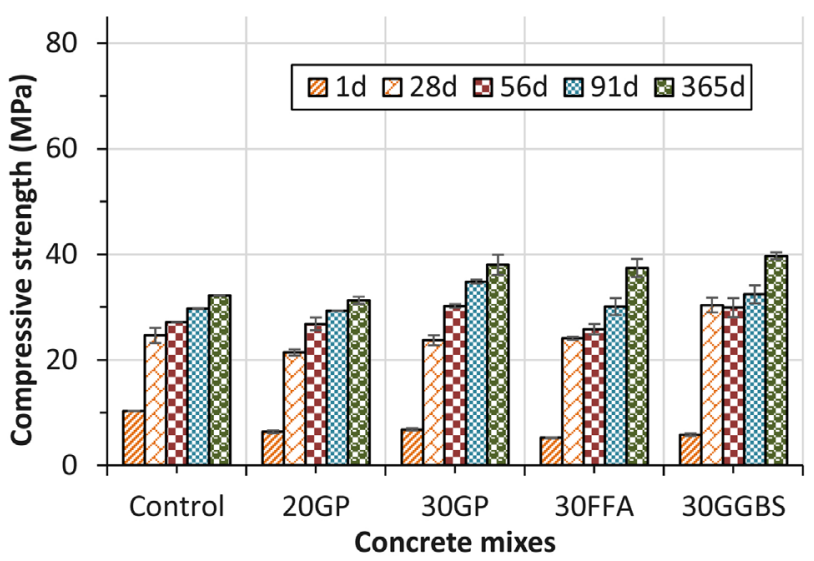

(b)

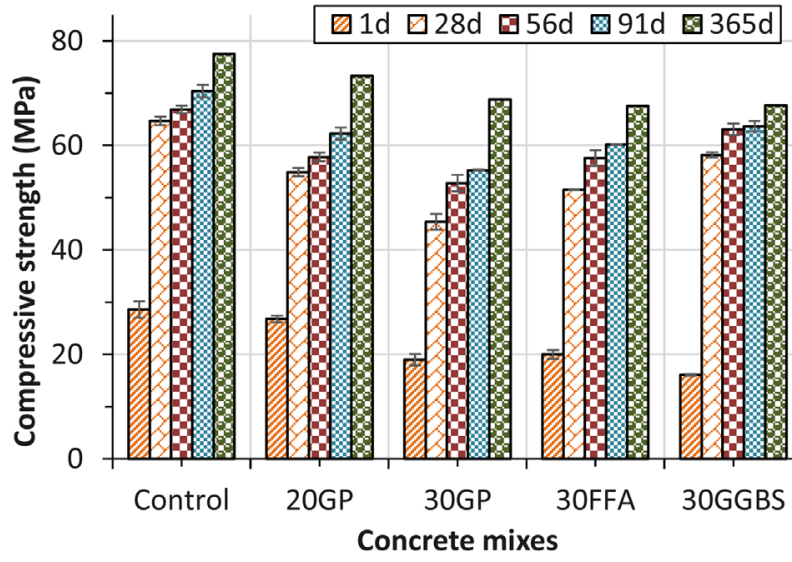

(d)

Figure 1. Compressive strength of different mixes according to the water to binder ratio.

0.35 have a strength lower than the control one even after 1 year. For w/b studied in this project no mineral additive provides a compressive strength which differs particularly from the others. The difference between strengths developed by the concretes with the different mineral additives is marginal. Yet, we should note that the development charts of the concrete strength incorporating the same rate of glass powder or fly-ash both almost show the same shape illustrating a quasi-similar effect of these additions on the compressive strengths. Concretes incorporating glass powder also have strength fairly satisfactory in comparison with the controls and with the other additives. Glass powder can be incorporated from $20 \%$ to $30 \%$ as partial substitution of cement in concrete without affecting its compressive strength in medium or long terms.

\subsection{Chloride Ion Permeability}

Permeability to chloride is a test commonly used to make a quantitative assessment of the concrete permeability. The basic principle of the test is to determine the total charges crossing the sample after 6 hours, subjected to a voltage difference of $60 \mathrm{~V}$. The charges measured on each concrete is correlated with its permeability. The increase in the charges induces more permeable concrete. Figure 
2(a) and Figure 2(b) show the total charges measured on concretes studied respectively at 56 and 91 days. Permeability of concrete incorporating mineral additions at 56 days is reduced dramatically compared to that of control concrete. For all concretes studied, the decrease in permeability from 56 to 91 days of wet curing is marginal. Permeability of concrete at 56 days with added minerals is almost similar to the one of 91 days. This observation shows that the high permeability reduction occurred in the first 56 days of wet curing. At 56 and 91 days, a quite perceptible difference can be observed on permeabilities of control concrete with different $w / b$ while no change or marginal difference was observed with different $\mathrm{w} / \mathrm{b}$ for concrete containing same rate of mineral additions. The permeabilities of these concretes with SCMs are almost similar regardless of w/b. At 56 days of wet curing, concrete without SCMs present permeability ranging

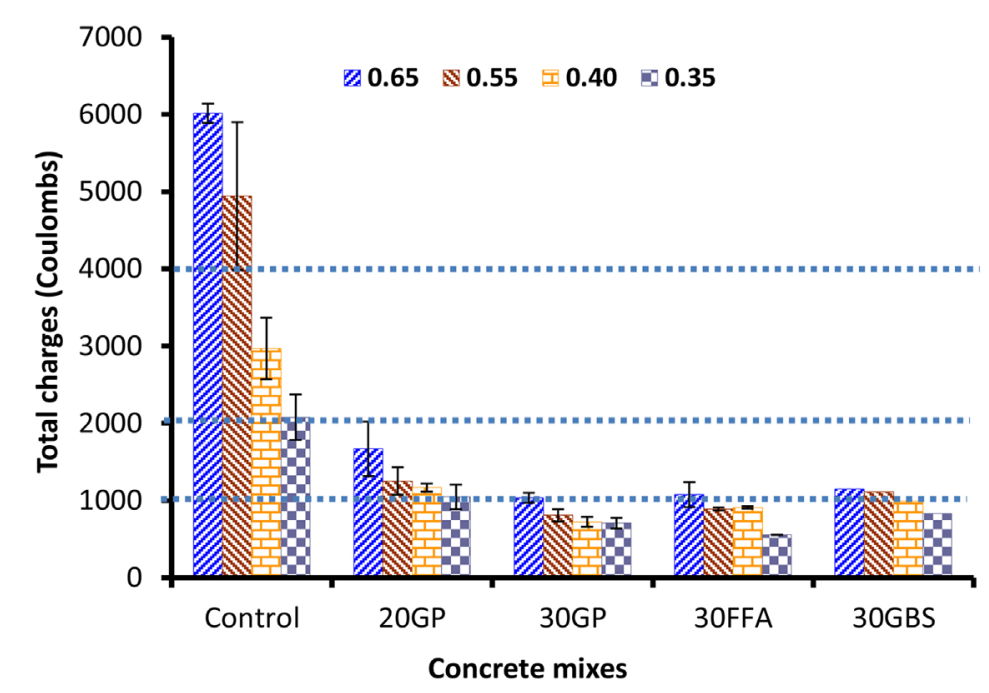

(a)

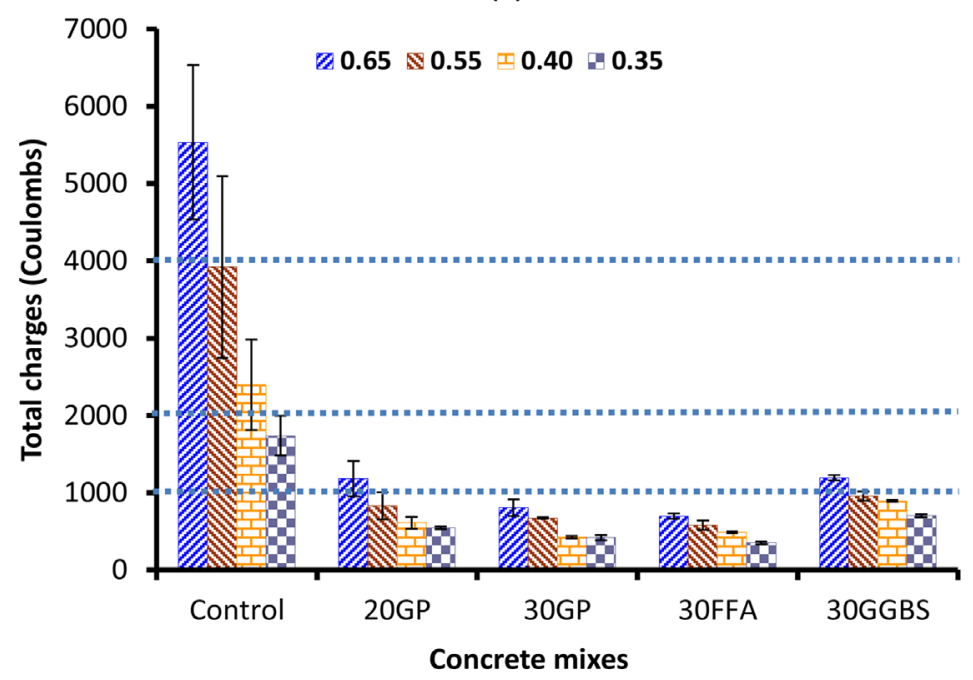

(b)

Figure 2. Chloride ions permeability of concrete: (a) at 56 days and (b) at 91 days. The permeability ranges separated by dotted lines and identified as 1 , 2, 3 and 4 correspond respectively to high, moderate, low and very low permeability. 
from high to moderate depending on the w/b ratio, whereas those of concretes containing mineral additives are among the class of low and very low permeability depending on the $\mathrm{w} / \mathrm{b}$ ratio and the type of mineral addition. The decrease of permeability in the presence of SCMs is significantly and permanently higher, as concrete incorporating 30\% mineral additives exhibit permeability of 2 to 6 times lower than those of control concrete depending on their $w / b$ ratio. The significant decrease in permeability observed in the presence of additions result from several phenomena related to their reaction mechanisms including filler effect, pozzolanic reaction and the ability of the mineral additions to fix chlorides. Actually, some SCMs such as fly ash develop filler effect as well as pozzolanic effect. Because of its fineness and the spherical shape of the particles, it is well inserted between the grains reducing thus intergranular voids. It contributes therefore to the densification of the cement matrix. Fly ash promotes refining pores, reducing the penetration of water and the increase in electrical resistivity [25].

All SCMs are known for their pozzolanic activity. Their pozzolanic reaction transforms large $\mathrm{CH}$ crystals by producing additional $\mathrm{CSH}$ that strengthen bonds between the particles by filling pores. In addition, transformation of portlandite to CSH causes a reduction in the size of grains (grain refiner) and the filling of pores by CSH additional causes a reduction in the size of the pores (pore refining). The refining of grains and pores generates a more segmentation of the pores and therefore making denser cement matrix. This segmentation of pores reduces the preferred path or the mobility of chloride ions. This is reflected by the significant reduction in permeability of concrete in the presence of SCMs. The significant reduction of the permeability of concrete in the presence of additions increases their resistance to penetration of external agents and thus enhancing its durability against these aggressive agents.

Although concretes containing $30 \%$ of different mineral additions have permeabilities of same order (same category class), it is remarkable to note, however, that the lowest permeability values are observed in concretes containing 30\% glass powder. The effects of different additions on the chloride permeability of concrete are similar.

\subsection{Chloride Ions Diffusion}

Diffusion of chloride ions in concrete presented in Figure 3 shows that the diffusion coefficient of chloride ions in concrete increases with increasing the w/b ratio for all concretes. This increase is very low for concrete incorporating 30\% glass powder showing that diffusion coefficients are almost identical regardless of the w/b. All concrete incorporating additions exhibit lower diffusion coefficient than control concrete suggesting the reduction of diffusion in the presence of additions. The lowest diffusion coefficients are recorded in concrete incorporating $30 \%$ glass powder, describing the largest ability of glass powder to reduce the chloride ions diffusion compared to other SCMs. The reduction of the diffusion coefficient observed in the presence of additions is due to their pozzolanic 


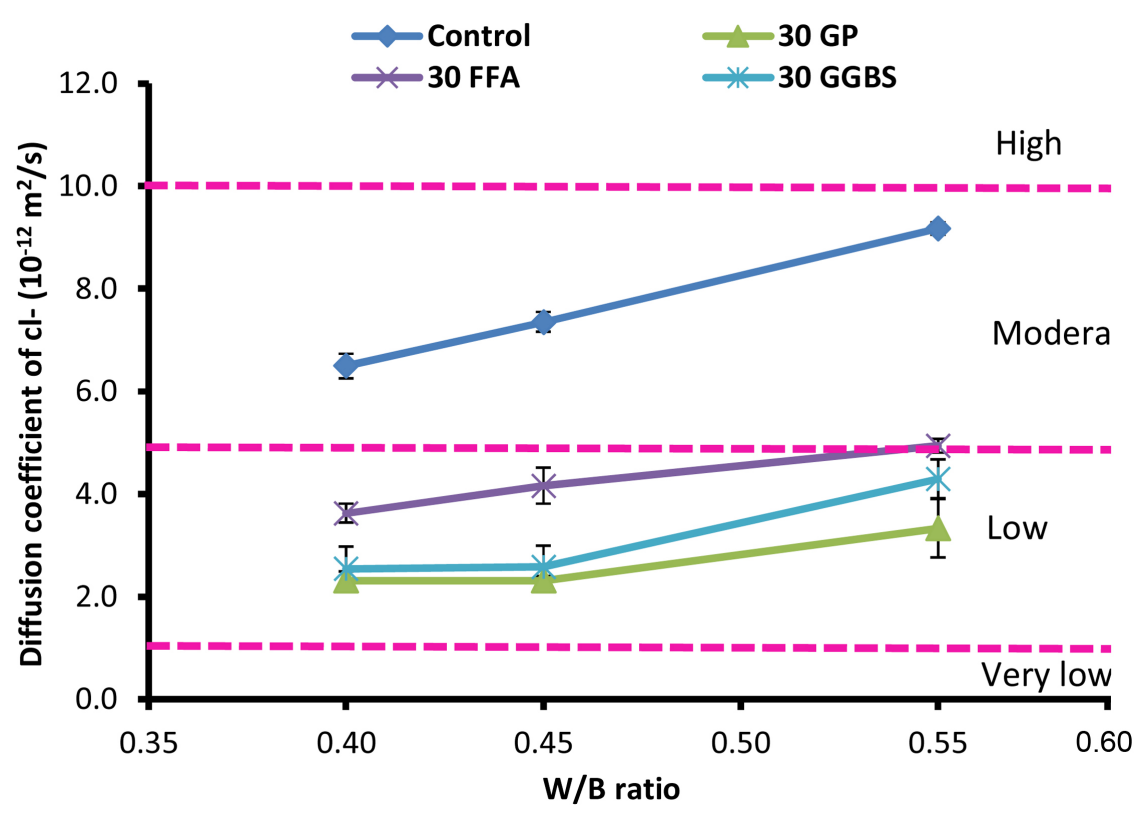

Figure 3. Chloride ions diffusion coefficient of concrete after 56 days moisture curing.

activity and their ability to fix chlorides.

These results are in accordance with the ones observed by Leng et al. [25] who have shown a reduction in the diffusion of chloride ions in concrete incorporating $20 \%$ fly ash or $30 \%$ slag. In addition, they also reported an increase in diffusion with $\mathrm{w} / \mathrm{b}$ in the control concrete and in concrete containing mineral additions.

\section{Discussion}

Figure 4 shows the compressive strength and the chloride ion permeability at 56 days for different concretes studied as a function of w/b. The age of 56 days was chosen as supplementary cementitious materials are known to better develop their performance from this age. It allows to analyze the effect of $w / b$ ratio and the type of binder on each of these properties of concrete. Whatever the type of binder, the compressive strength decreases with the increase of $w / b$. This reflects an increase of the porosity of concretes with increasing w/b. The compressive strength and porosity vary inversely.

The chloride ions permeability of control concrete follows the well-known classic trend. It increases with the increase of $\mathrm{w} / \mathrm{b}$ due to the enhancement in the size and volume of pores. However, concrete containing SCMs exhibit similar permeability whatever $\mathrm{w} / \mathrm{b}$, showing the reduction of pores interconnectivity further to the pozzolanic reaction of additions.

Figure 5(a) shows the variation of the chloride permeability of samples after 91 days of age as a function of compressive strength of samples of 56 days. This allows to define a zone of relative durability requirements as recommended by CSA A23.1-14 for classes C1 exposure as defined in this standard. Exposure class $\mathrm{C} 1$ includes the reinforced concrete exposed to chlorides and with or without subject to freeze-thaw. 


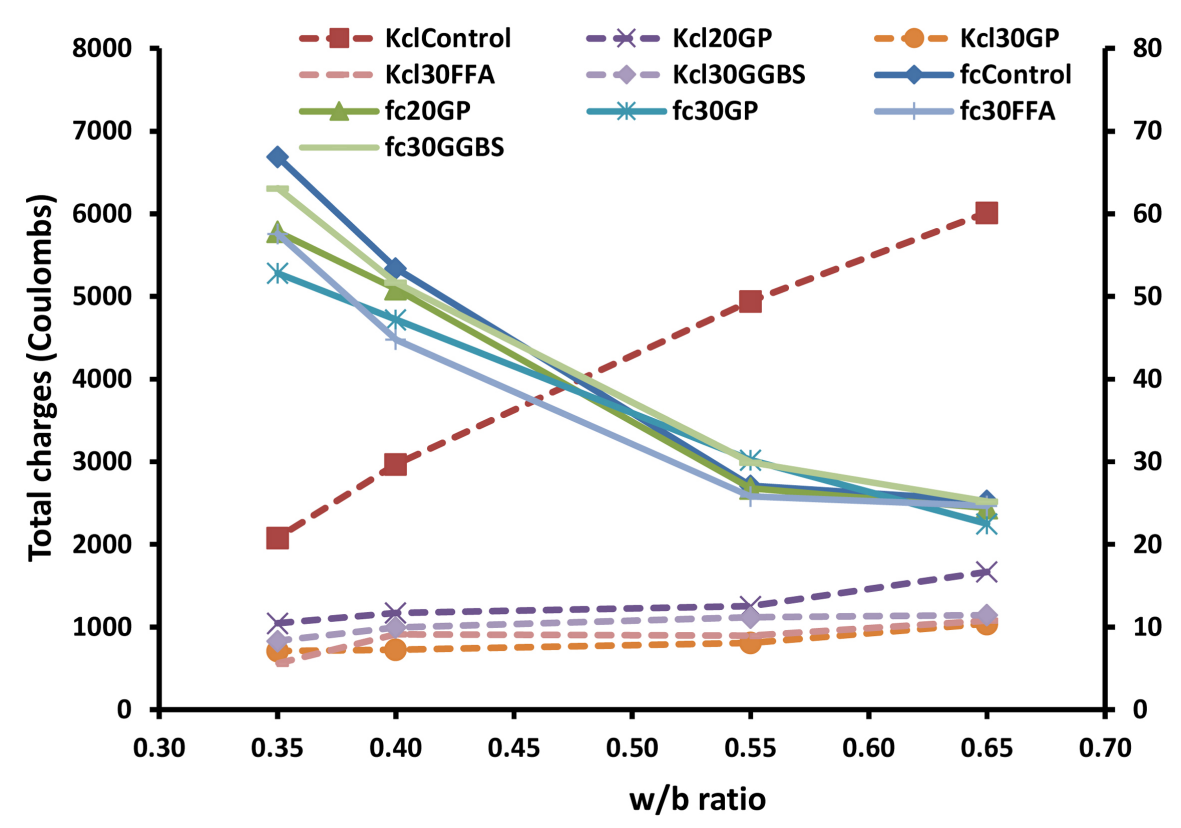

Figure 4. Compressive strength and chloride ions permeability versus $\mathrm{w} / \mathrm{b}$ ratio. $\mathrm{Kcl}$ is referred to the total charge and fc corresponded to the compressive strength.

All concrete located in the small rectangle defining the area of good durability meet the durability requirements of the standard and may be used for reinforced concrete without damaging its strength against the penetration of aggressive external agents. Figure 5(b) presents a correlation between permeability and diffusion of chloride ions for concrete after 56 days of age. Permeabilities of control concrete are very well correlated with their diffusion coefficients with a correlation coefficient $R^{2}=0.99$. However, a cloud of points concentrated in the same zone is observed in the case of concrete containing mineral additions. They vary very little with the variation of $\mathrm{w} / \mathrm{b}$. This is in line with the pozzolanic reaction of those SCMs which allow the reduction of the interconnection of pores by filling them with the supplementary C-S-H formed.

This study shows that, as new alternative cementitious material, the glass powder exhibits similar or even better performance than the other SCMs studied. Therefore, the glass powder could be used as cement addition where ordinary SCMs become scarce.

\section{Conclusions}

This work, based on the study of the effect of glass powder on concrete properties, showed a good behavior of this mineral addition compared to the conventional SCMs. As expected, the increase in $\mathrm{w} / \mathrm{b}$ ratio lowers the compressive strength of concrete containing GP at early age. However, the development of compressive strength seems to be more prominent with the increase of $w / b$ ratio in the presence of glass powder in the long-term. This behavior reflects a slow and continuous pozzolanic activity of the glass powder in mixtures with enough free water available. In addition, the improvement of concrete durability in the 


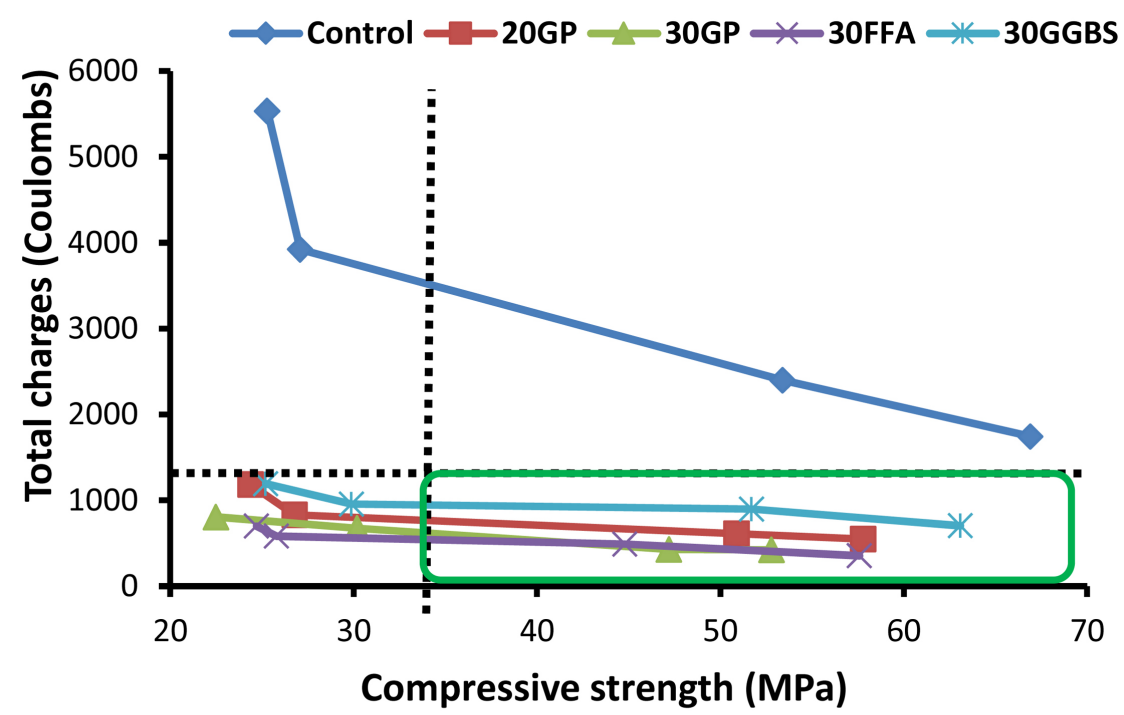

(a)

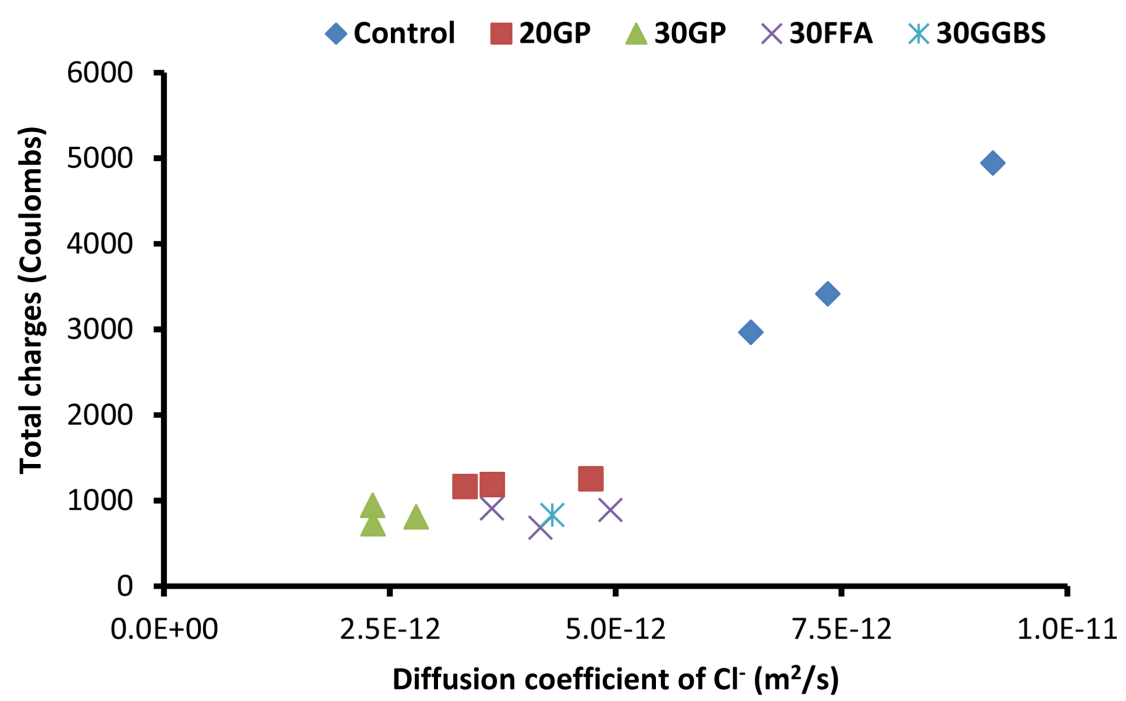

(b)

Figure 5. Curve showing correlation between chloride ions permeability and (a) compressive strength; and (b) diffusion coefficient.

presence of GP is more important with increasing its rate of incorporation and/or w/b ratio.

When comparing the effect of GP with the other SCMs, one can observe that GP actions on concrete properties are similar to those of class F fly ash. Slag seems to develop significant effects at an early age in comparison with the other additions, but in the long term (from 91 days) their effects are equivalent.

As glass powder develops quite similar or even better effects than other SCMs studied on concrete properties, it could be properly used as an alternative supplementary cementitious material where conventional SCMs are not available.

\section{Acknowledgements}

The research results presented here are performed in the framework of a re- 
search chair offered by the Sociéte des Alcools du Québec (SAQ). The authors would like to express their sincere thanks to the SAQ for its valuable financial support for this project.

\section{References}

[1] Feldman, R.F. (1981) Pore Structure Formation during Hydration of Fly Ash and Slag Cement Blends. In: Diamond, S., Ed., Effects of Fly Ash Incorporation in Cement and Concrete, Materials Research Society, Pittsburgh, PA, 124-133.

[2] Manmohan, D. and Metha, P.K. (1981) Influence of Pozzolanic, Slag and Chemical Admixtures on Pore Size Distribution and Permeability of Hardened Cement Pastes. Cement Concrete and Aggregates, 3, 63-67.

[3] Sellevold, E.J., Bager, D.H., Klitgaard Jensen, E. and Knudsen, T. (1982) Silica Fume Cement Paste-Hydration and Pore Structure. In: Silica Fume Cement Paste-Hydration and Pore Structure. Condensed Silica Fume in Concrete, Norwegian Institute of Technology, University of Trondheim, Norway, Report BML 82-610, 19-50.

[4] Marsh, B.K., Day, R.L. and Bonner, D.G. (1985) Pore Structure Characteristics Affecting the Permeability of Cement Paste Containing Fly Ash. Cement and Concrete Research, 15, 1027-1038.

[5] Cur, R. (1991) Fly Ash as Addition to Concrete. Vol. 144, Center for Civil Engineering Research and Codes Edition, Gouda, The Netherlands, 99.

[6] Tumidajski, P.J. (2006) Effect of Slag, Silica Fume, and Finishing on the Sorptivities of Field Concrete. Canadian Journal of Civil Engineering, 33, 1022-1026.

http://www.nrcresearchpress.com/doi/pdfplus/10.1139/106-048 https://doi.org/10.1139/106-048

[7] Shayan, A. and Xu, A. (2004) Value-Added Utilization of Waste Glass in Concrete. Cement and Concrete Research, 34, 81-89.

[8] Reindl, J. (1998) Report by Recycling Manager. Dane County, Department of Public Works, Madison, USA.

[9] Pattengil, M. and Shutt, T.C. (1973) Use of Ground Glass as a Pozzolan. Albuquergue Symptom on Utilisation of Waste Glass in Secondary Products, Albuquerque, New Mexico, USA, 24-25 January 1973, 137-153.

[10] Samtur, H.R. (1974) Glass Recycling and Reuse. Report 17, University of Wisconsin, Madison Institute for Environmental Studies.

[11] Shao, Y., Lefort, T., Moras, S. and Rodriguez, D. (2000) Studies on Concretes Containing Ground Waste Glass. Cement and Concrete Research, 30, 91-100.

[12] Meyer, C., Baxter, S. and Jin, W. (1996) Alkali-Silica Reaction in Concrete with Waste Glass as Aggregate. In: Chong, K.P., Ed., Materials for a New Millennium, Proceedings of ASCE Materials Engineering Conference, Washington DC, 13881394.

[13] Meyer, C., Baxter, S. and Jin, W. (1996) Potential of Waste Glass for Concrete Masonry Blocks. In: Chong, K.P., Ed., Materials for a New Millennium, Proceedings of ASCE Materials Engineering Conference, Washington DC, 666-673.

[14] Shi, C., Wu, Y., Riefler, C. and Wang, H. (2005) Characteristics and Pozzolanic Reactivity of Glass Powder. Cement and Concrete Research, 35, 987-993.

[15] Idir, R., Cyr, M. and Tagnit-Hamou, A. (2011) Pozzolanic Properties of Fine and Coarse Color-Mixed Glass Cullet. Cement and Concrete Composites, 33, 19-29.

[16] Zidol, A. (2009) Optimisation de la finesse de la poudre de verre dans les systèmes cimentaires binaires. Master's Thesis, University of Sherbrooke, Canada. 
[17] Shayan, A. and Xu, A. (2006) Performance of Glass Powder as a Pozzolanic Material a Field Trial on Concrete Slabs. Cement and Concrete Research, 36, 457-468.

[18] Aladdine, F. (2009) Propriétés mécaniques et durabilité des bétons incorporant du verre finement broyé. Master's Thesis, University of Sherbrooke, Canada.

[19] Kateb, M.L. (2009) Utilisation des granulats de verre dans la fabrication des bétons architecturaux, cas de briques en bétons. Master's Thesis, Sherbrooke, Canada.

[20] Taha, B. and Nounu, G. (2008) Properties of Concrete Contains Mixed Colour Waste Recycled Glass as Sand and Cement Replacement. Construction and Building Materials, 22, 713-720.

[21] Idir, R., Cyr, M. and Tagnit-Hamou, A. (2010) Use of Fine Glass as ASR Inhibitor in Glass Aggregate Mortars. Construction and Building Materials, 24, 1309-1312.

[22] Zidol, A., Pavoine, A. and Tagnit-Hamou, A. (2012) Effect of Glass Powder on Concrete Permeability. International Congress on Concrete Durability, Trondheim, Norway, 18-21 June 2012, 15 p.

[23] Schwarz, N., Cam, H. and Neithalath, N. (2008) Influence of a Fine Glass Powder on the Durability Characteristics of Concrete and Its Comparison to Fly Ash. Cement and Concrete Composites, 30, 486-496.

[24] Hussain, S.E. and Rasheeduzzafar (1994) Corrosion Resistance Performance of Fly Ash Blended Cement Concrete. ACI Materials Journal, 91, 264-272. http://esatjournals.net/ijret/2012v01/i03/IJRET20120103042.pdf

[25] Leng, F., Feng, N. and Lu, X. (2000) An Experimental Study on the Properties of Resistance to Diffusion of Chloride Ions of Fly Ash and Blast Furnace Slag Concrete. Cement and Concrete Research, 30, 989-992.

\section{Submit or recommend next manuscript to SCIRP and we will provide best} service for you:

Accepting pre-submission inquiries through Email, Facebook, LinkedIn, Twitter, etc. A wide selection of journals (inclusive of 9 subjects, more than 200 journals)

Providing 24-hour high-quality service

User-friendly online submission system

Fair and swift peer-review system

Efficient typesetting and proofreading procedure

Display of the result of downloads and visits, as well as the number of cited articles

Maximum dissemination of your research work

Submit your manuscript at: http://papersubmission.scirp.org/

Or contact njgc@scirp.org 